\title{
The income elasticity of lottery revisited: A worldwide perspective
}

\author{
Levi Pérez ${ }^{1, *} \bullet$ Álvaro Muñiz ${ }^{2}$ \\ ${ }^{1}$ University of Oviedo, Spain \\ ${ }^{2}$ University of Cantabria, Spain
}

Received: 22 March 2021

Revised: 22 June 2021

Accepted: 9 September 2021

\begin{abstract}
Using panel data information from The WLA Global Lottery Data Compendium this paper estimates aggregate demand functions for lottery tickets in order to examine specific world region differences in the income elasticity of lottery. The analysis uses a panel data quantile regression approach. The estimated elasticities are compared across income quartiles and world regions. The results provide evidence that a significant variation in the income elasticities across both geographic areas and the income distribution exists. Also, a clear heterogeneity in the incidence of lottery expenditures is observed. Overall, it is found that lottery is a normal good.
\end{abstract}

Keywords: Lottery demand; Income elasticity; International comparison; Quantile regression JEL Classification Codes: E20, L83, O57

\section{Introduction}

The income elasticity of lottery, i.e., the change in lottery sales associated with a change in income, is of interest for several reasons. First, income is one of the key determinants of lottery expenditure, and understanding the determinants of lottery expenditure is important because of the extreme popularity of lottery and the high level of purchase involvement in countries around the world (normally a positive relationship between consumers' income and the demand for lottery is observed). Second, the income elasticity of lottery is an important parameter for policy analysis in order to identify patterns in lottery expenditure across the income distribution - e.g. income elasticities less than one indicate a less than proportional percentage change in sales given a 1-percent change in income suggesting lottery as a regressive implicit tax. Critics of government sponsored lotteries frequently claim that low-income individuals purchase a disproportionate number of lottery tickets, adding additional emphasis to research on the relationship between income and lottery spending (Perez and Humphreys, 2011).

Moreover, lotteries are challenging markets to understand and model since they are more complex than it appears at first glance. Beyond the public interest in lotteries as an alternative

\footnotetext{
*Corresponding author. E-mail: lperez@uniovi.es.

Citation: Pérez, L., and Muñiz, Á. (2021) The income elasticity of lottery revisited: A worldwide perspective, Economics and Business Letters, 10(4), 403-407.
}

DOI: 10.17811/ebl.10.4.2021.403-407 
method for the government to raise revenue - the parameters of lottery games are generally set to maximize revenue to the state (Gulley, 2018) -, the economics of lottery markets is an interesting field to study since it contains a specific paradox: playing the lottery seems to be economically irrational. For an analysis of the factors affecting lottery adoptions, see Alm et al. (1993) or Jackson et al. (1994). A more recent review of the literature could be found in Grote and Matheson (2011) and Pérez and Humphreys (2013).

Although much research has been done on lottery markets and empirical estimation of aggregate demand functions is common in the lottery literature (e.g., Mikesell, 1989; Cook and Clotfelter, 1993; Price and Novak, 2000; Garrett and Coughlin, 2009; Ghent and Grant, 2010; among other studies commonly referenced in the literature), there is a lack of studies of lotteries from an international perspective. Apart from Garrett (2001) and Matheson and Grote (2009) that provide cross-country studies of lottery markets, most of the studies published to date on lotteries have been made at either a national or regional level.

This paper adds to the scarce number of comparative studies on lottery demand among different jurisdictions. Compared to previous literature, the use of panel data allows to examine specific world region differences highlighting the similarities or differences in the stability of lottery revenues worldwide. Its main contribution is to provide estimates of income elasticities (by income quartiles) taking into account different gambling regulatory environments across world regions. As previously discussed, this is a relevant policy issue and can be considered as the most common statistic in the debate on the efficacy of lotteries as an appropriate means of government finance, as it provides evidence on the distributional burden (by income) of lottery expenditures (Garrett, 2016).

\section{Data sample}

Data on lottery markets consists of a balanced panel of 60 nationwide lottery operators, from 53 different countries worldwide, located in 4 world regions, and observed over 5 years (between 2013 and 2017). Information on lottery sales come from The WLA Global Lottery Data Compendium, an annual review of the lottery industry based on data from the World Lottery Association (WLA) members. Aggregate data on market size (population) and income (GDP) has been obtained from World Bank Open Data.

It should be noted that data sample were restricted to national lottery operators that have reported their figures to the WLA during the sample period. Regional operators have been excluded because their area of activity is not well specified or because of a lack of information. Similarly, US lottery operators were not considered for data availability reasons.

Table 1 summarizes relevant figures per world region from the lottery markets (operators and countries) considered, while Table 2 displays the variation of per capita lottery sales through the income distribution. Note that lottery sales revenue and income (GDP) were converted into USD by using the corresponding average annual exchange rate and then deflated by each country consumer price index to transform them in real terms. Consequently, these two variables are measured in 2011 USD.

It can be observed that, during the sample period, lottery ticket sales account on average for at least $0.46 \%$ of each country's GDP, reaching $1 \%$ of Asian countries GDP. Furthermore, per capita lottery sales overall seem to increases as going up through the income quartiles. However, different patterns across world regions can be noted, and even in both African and LAC countries median sales declines in some of the top quartiles of per capita GDP.

\section{Model specification and results}

The aim of this paper is to examine variation in the income elasticities of lottery across income quartiles for different world regions. The general methodology will involve, then, estimation of quantile regression (Machado and Santos Silva, 2019) of per capita lottery sales on a vector of 
Table 1. International comparison of lottery markets by world region.

\begin{tabular}{lrrrrr}
\hline \hline & Africa & Asia & Europe & LAC $^{\text {a }}$ & Global \\
\hline \# countries & $7^{\mathrm{b}}$ & $9^{\mathrm{c}}$ & $29^{\mathrm{d}}$ & $8^{\mathrm{e}}$ & 53 \\
Median GDP (mil- & 26,418 & 710,951 & 229,211 & 256,937 & 254,924 \\
lion 2011 USD) & 8 & 11 & 33 & 8 & 60 \\
\# lottery operators ${ }^{f}$ & 211 & 2,026 & 614 & 396 & 558 \\
Median sales (mil- & $0.77 \%$ & $1.01 \%$ & $0.54 \%$ & $0.46 \%$ & $0.65 \%$ \\
lion 2011 USD) & Sales/GDP &
\end{tabular}

Notes: ${ }^{\mathrm{a}}$ LAC stands for Latin America and the Caribbean. ${ }^{\mathrm{b}}$ Burkina Faso, D.R. of the Congo, Ghana, Morocco, Mauritania, Niger and Togo. ${ }^{\mathrm{c}}$ China, Hong Kong SAR, India, Israel, Japan, Lebanon, Philippines, Thailand and Sri Lanka. ${ }^{\mathrm{d}}$ Austria, Belarus, Bosnia and Herzegovina, Bulgaria, Croatia, Cyprus, Czech Republic, Denmark, Estonia, France, Greece, Hungary, Iceland, Italy, Latvia, Lithuania, Luxembourg, Malta, Norway, Poland, Portugal, Romania, Serbia, Slovakia, Slovenia, Spain, Sweden, Turkey and United Kingdom. ${ }^{\mathrm{e}}$ Brazil, Chile, Ecuador, Mexico, Panama, Peru, Trinidad and Tobago and Saint Lucia. ${ }^{f}$ Countries with two nationwide lottery operators include: Denmark, Italy, Spain, Sweden, Morocco, China and Japan.

Table 2. Median per capita lottery sales by quartiles of per capita GDP (2011 USD).

\begin{tabular}{rrrrrr}
\hline \hline & Africa & Asia & Europe & LAC & Global \\
\hline $\begin{array}{c}\text { All } \\
\text { quartile }\end{array}$ & 12.71 & 26.90 & 92.33 & 24.55 & 53.24 \\
0.25 & 2.08 & 15.59 & 25.87 & 15.33 & 16.04 \\
0.5 & 11.28 & 21.47 & 53.82 & 22.91 & 20.51 \\
0.75 & 19.22 & 26.00 & 78.78 & 18.36 & 30.54 \\
\hline \hline
\end{tabular}

each world region countries characteristics (GDP; population) and considering each country's geographic area. Quantile methods allow to relax the common assumption in OLS that associations between independent and dependent variables are the same at all levels and may lead to more robust results as the interest is not in the mean but in the median. Accordingly, the following specification is estimated:

$$
y_{i t}=f\left(x_{j t}, w_{j}, z_{t}\right)
$$

, where lottery sales revenue for operator $i$ in year $t\left(y_{i t}\right)$, is described as a function of country $j$ specific variables in which operator $i$ operates in year $t\left(x_{j t}\right)$, a set of categorical variables that stand for the world region in which country $j$ is $\left(w_{j}\right)$, and time-effect dummy variables $\left(z_{t}\right)$.

Table 3. Income elasticity of demand for lottery.

\begin{tabular}{|c|c|c|c|c|c|}
\hline \multicolumn{6}{|c|}{ Dependent variable: $(\log )$ (per capita) Lottery sales } \\
\hline & (1) & (2) & & & \\
\hline & GDP & Africa*GDP & Asia*GDP & Europe*GDP & LatAm*GDP \\
\hline 0.25 quartile & $\begin{array}{r}0.914 * * * \\
(0.146)\end{array}$ & $\begin{array}{r}0.752 * * * \\
(0.244)\end{array}$ & $\begin{array}{r}1.054 * * * \\
(0.339)\end{array}$ & $\begin{array}{r}1.106^{* * *} \\
(0.235)\end{array}$ & $\begin{array}{r}2.012 * * * \\
(0.457)\end{array}$ \\
\hline 0.5 quartile & $\begin{array}{r}1.057 * * * \\
(0.139)\end{array}$ & $\begin{array}{r}0.583 * * \\
(0.230)\end{array}$ & $\begin{array}{r}1.409 * * * \\
(0.322)\end{array}$ & $\begin{array}{r}1.136 * * * \\
(0.221)\end{array}$ & $\begin{array}{r}2.208 * * * \\
(0.430)\end{array}$ \\
\hline 0.75 quartile & $\begin{array}{r}1.260 * * * \\
(0.164)\end{array}$ & $\begin{array}{r}0.216 \\
(0.264)\end{array}$ & $\begin{array}{r}2.179 * * * \\
(0.365)\end{array}$ & $\begin{array}{r}1.199 * * * \\
(0.255)\end{array}$ & $\begin{array}{r}2.634 * * * \\
(0.495)\end{array}$ \\
\hline
\end{tabular}

Note: Main independent variable: (1) (log) (per capita) (real) GDP and (2) its interaction with corresponding world region dummy. Controls include: (log) population; world region dummies; year dummies and a constant. Observations $n=300$; lottery operators $i=60$. **significant at $5 \%$; ***significant at $1 \%$. All explanatory variables are in natural logarithm form. 
The first panel in Table 3 shows the global income elasticity of demand for lottery tickets given the functional form chosen for the demand equation, the estimated coefficient of the income variables in logs could be interpreted as short-run elasticities. Estimates are based in considering all the countries worldwide as one unique jurisdiction, and so GDP quartiles are defined through the entire all-countries distribution. The second panel display estimates for an alternative model specification in which the income variable (GDP) is interacted with a respective binary world region dummy to measure differences in the income elasticity of demand across geographic areas. Here, estimated coefficients can be interpreted equivalent to if only the countries in that world region were considered.

The results for all the considered specifications show a strong relationship between lottery expenditure and income but indicating a wide range of income elasticities among regions. Apart from Africa, lottery income elasticity worldwide increases with the income quartile. In Asia, Europe and LAC lottery demand rises more than proportionate to a change in income. However, in Africa lottery sales increase less than proportionately with income, which makes the lottery, as an implicit tax, regressive.

As for the Caribbean and Latin America region, with an income elasticity clearly above two, lottery demand seems to be very sensitive to changes in income and could be considered somehow progressive. Estimates indicate that the implicit tax generated by the lottery may fall on upper income quartiles. A similar pattern, but lower values, is observed in Asia.

The null hypothesis of an income elasticity equal to one cannot be rejected for European lottery markets $(\mathrm{p}=0.513)$, suggesting a certain proportionality of lottery expenditure to income.

Overall, the estimated coefficients show a clear heterogeneity across world regions in terms of the income elasticity of demand for lottery, but suggesting in all cases that the lottery is a normal good worldwide. Although the study of the causes of that heterogeneity lies beyond the scope of this paper, they could be partly explained by social or cultural differences.

With respect to the population variable, a negative effect is obtained in all cases (estimated coefficients range from -0.252 to -0.150). This could reflect a larger supply of alternative leisure activities (substitutes for the lottery and gambling in general) in highly populated jurisdictions.

\section{Limitations}

Although aggregate data can certainly be used to study changes in market demand due to changes in, say, market size and income, a critique of this analysis would be that using world regions country-level data to make inferences about individual behavior would assume that all consumers within a jurisdiction have identical preferences.

\section{Concluding remarks}

This paper contributes to the broad literature on lottery markets by providing an international comparison of the income elasticity of the demand for lottery across income quartiles and world regions. For all jurisdictions, lottery tickets are found to be normal goods. There is difference, however, in the magnitude of the income elasticities across both world regions and income classes.

Results provide not only interesting evidence of differences in demand for lottery products worldwide, but also implications for the implicit tax of lotteries over regions. In contrast to previous research, the implicit tax is progressive on average for most of considered lottery markets, but it is not progressive in all regions and this is an important distinction for policy makers in those jurisdictions.

More specifically, any examination of the welfare implications of lottery financed public expenditures should recognize the substantial context-dependent variation in the income elasticity. 


\section{References}

Alm, J., McKee, M. and Skidmore, M. (1993) Fiscal Pressure, Tax Competition, and the Introduction of State Lotteries, National Tax Journal, 46(4), 463-76.

Cook, P. and Clotfelter, C. (1993) The peculiar scale economies of lotto, American Economic Review, 83(3), 634-643.

Garrett, T. (2001) An international comparison and analysis of lotteries and the distribution of lottery expenditures, International Review of Applied Economics, 15(2), 213-227.

Garrett, T. (2016) The (aggregate) demand for state lottery tickets: What have we really learned?, Contemporary Economic Policy, 24(3), 475-482.

Garrett, T. and Coughlin, C. (2009) Inter-temporal differences in the income elasticity of demand for lottery tickets, National Tax Journal, 62(1), 77-99.

Ghent, L. and Grant, A. (2010) The demand for lottery products and their distributional consequences. National Tax Journal, 63(2), 253-268.

Grote, K. and Matheson, V. (2011) The Economics of Lotteries: A Survey of the Literature, Working paper 1109. College of the Holy Cross, Department of Economics.

Gulley, O. (2018) The optimal structure of lotto games, Economics and Business Letters, 7(4), 156-161.

Jackson, J., Saurman, D. and Shughart II, W. (1994) Instant winners: Legal change in transition and the diffusion of state lotteries, Public Choice, 80(3-4), 245-263

Machado, J. and Silva, J. (2019) Quantiles via moments, Journal of Econometrics, 213(1), 145173.

Matheson, V. and Grote, K. (2009) Spreading the Fortune: The Distribution of Lottery Prizes across Countries, Working paper 0904. College of the Holy Cross, Department of Economics.

Mikesell, J. (1989) A note on the changing incidence of state lottery finance, Social Science Quarterly, 70(2), 513-521.

Perez, L. and Humphreys, B. (2011) The income elasticity of lottery: New evidence from micro data, Public Finance Review, 39(4), 551-570.

Perez, L. and Humphreys, B. (2013) The 'who and why' of lottery: empirical highlights from the seminal economic literature, Journal of Economic Surveys, 27(5), 915-940.

Price, D. and Novak, E. (2000) The income redistribution effects of Texas state lottery games, Public Finance Review, 28(1), 82-92. 